Article

\title{
Research on Flow-Induced Vibration and Energy Harvesting of Three Circular Cylinders with Roughness Strips in Tandem
}

\author{
Lin Ding 1,2,*(D), Qunfeng Zou ${ }^{1,2}$, Li Zhang ${ }^{1,2}$ and Haibo Wang ${ }^{1,2}$ \\ 1 Key Laboratory of Low-grade Energy Utilization Technologies and Systems of Ministry of Education of China, \\ Chongqing University, Chongqing 400044, China; qunfengzou@cqu.edu.cn (Q.Z.); \\ lizhang@cqu.edu.cn (L.Z.); haibowang@cqu.edu.cn (H.W.) \\ 2 School of Energy and Power Engineering, Chongqing University, Chongqing 400044, China \\ * Correspondence: linding@cqu.edu.cn; Tel.: +86-23-65103101
}

Received: 6 October 2018; Accepted: 29 October 2018; Published: 1 November 2018

check for updates

\begin{abstract}
The flow-induced vibration (FIV) of multiple cylinders is a common phenomenon in industry and nature. The FIV and energy harvesting of three circular cylinders in tandem are numerically studied by 2D-URANS simulations in Reynolds number range of 30,000 $<R e<105,000$. Simulation results match well with experiments in the tested cases. Four branches of FIV are clearly captured in the amplitude and frequency ratio curves of the three cylinders with roughness, including initial branch of vortex-induced vibration (VIV), VIV upper branch, transition from VIV to galloping, and galloping. It is shown that the vortices from downstream cylinder are strongly disrupted and modified by vortices of upstream cylinder. The third cylinder is almost suppressed in VIV initial branch. The $2 \mathrm{P}$ vortex pattern is observed for the first cylinder in the VIV upper branch. For $R e=90,000$ in the transition regime, the vortex patterns of the first and second cylinders are $2 \mathrm{P}+4 \mathrm{~S}$ and $2 \mathrm{P}+2 \mathrm{~S}$, respectively. In the galloping branch, the shear layer motion is in synchronization with the motion of the cylinder, and the maximum amplitude of $2.8 D$ is reached by the first cylinder. The total converted power of the three cylinders increases with $U_{\text {water }}^{*}$ both in the simulation and experiment. For the three cylinders, the maximum power reaches up to $85.26 \mathrm{~W}$ with the increase of Reynolds number. The energy conversion efficiency is stable and higher than $35 \%$ in the starting region of VIV upper branch, and the maximum value of $40.41 \%$ is obtained when $R e=40,000$.
\end{abstract}

Keywords: flow-induced vibration; energy harvesting; energy conversion efficiency; three cylinders; tandem

\section{Introduction}

Flow-induced vibration (FIV) has attracted extensive attention and has become one of the study focuses in the theory and application of fluid-structure interaction. FIV exists in various fields, such as heat exchangers, cables, chimneys, and long-span suspension bridges [1,2]. In practical engineering, suppression of FIV has always been studied for its fatigue damage to structure. At present, in order to overcome the energy challenges, many new technologies of harnessing clean energy have been developed, including geothermal, biomass, solar energy, etc. [3]. Different from previous studies, Bernitsas MM et al. [4,5] invented a converter to harvest clean energy using FIV, which was called VIVACE (Vortex Induced Vibration for Aquatic Clean Energy). This converter was further developed in the MRELab (Marine Renewable Energy Laboratory) at the University of Michigan [6,7]. The VIVACE converter can be simplified as a single cylinder supported on springs with an energy harvest system. Compared with other energy collecting devices, it can convert marine hydrokinetic energy in currents 
even at low speed of $0.4 \mathrm{~m} / \mathrm{s}$. The conversion process is the energy of transportation flow converted to mechanic energy firstly and subsequently generate electrical energy. The mass, stiffness, and damping which are the three key parameters of the single cylinder converter have obvious impact on the FIV response and energy harvesting [8,9]. For the purpose of enhancing the amplitude of the cylinder in FIV, Passive Turbulence Control (PTC) was applied in experimental tests in MRELab [10]. Park et al. [11,12] presented the PTC-to-FIV Map. The back-to-back vortex-induced vibration (VIV) and galloping are achieved when PTC thickness is approximately equal to that of the boundary layer. Preliminary studies on bluff bodies with different cross sections in FIV indicate that the vibration intensity of PTC-cylinder and Q-trapezoid I are obviously stronger than square cylinder and triangle cylinder [13]. And in comparison with the single cylinder system, the power density of VIVACE can be improved by a multiple cylinder system and more hydrokinetic energy can be harvested [7].

VIV and galloping are two kinds of the most common FIV phenomena. The elastically mounted cylinder will oscillate periodically for the alternated vortex shedding. The response of the amplitude of FIV would be stronger when the vortex shedding frequency is close to the oscillating frequency of the cylinder. VIV is a self-excited oscillation with limited amplitude which caused by periodical forces on the cylinder of oscillatory system. Khalak and Williamson [14-16] classified the region of VIV into three branches including the initial, upper, and lower branches. The reviews by Huang S [17], Williamson and Govardhan [18,19], Guilmineau E [20], Wu et al. [21] and Bearman [22] provide more detailed information for vortex-induced vibration of a single cylinder.

Unlike VIV, galloping is an unsteady FIV phenomenon which is not caused by shed vortices, but rather by the motion of the shear layers on the surface of a cylinder. Bluff body with only an asymmetry section could lead to galloping oscillation and its features are high-amplitude and low-frequency. Gallop cannot achieve an isolated smooth circular cylinder in FIV [23]. Moreover, Alonso et al. [24-26] show that the cross-sectional geometry and the attack angle of fluid are the two key factors to influence galloping by experimental investigation. Nakamura et al. [27] and Chang et al. [10] found that galloping may be initiated by a circular body with attachments. Furthermore, galloping of the cylinder in FIV may also occur when the oscillation of the cylinder is affected by other cylinders [28]. The above studies verify that galloping in FIV can be caused by asymmetry of the buff body and attachments on it, or influences of other cylinders in upstream flow.

Flow interference in multiple bluff bodies is a common subject for its wide interest in practice. Griffith et al. [29] pointed out there is an important difference between the vortex-induced vibration of multiple cylinders and a single cylinder. The two cylinders in tandem is the simplest configuration of multiple cylinders system. The interference between cylinders depends on the arrangement of two cylinders and the attack angle of incoming flow [29-31]. For two cylinders positioned in tandem, the spacing between cylinders plays a very important role in FIV response. The FIV responses of two cylinders in tandem with different spacing are conducted by Kim et al. [32]. They found that the response of upstream cylinder is similar to an isolated cylinder when the spacing between two cylinders is larger than 2.7 diameters. Moreover, the disturbance of two cylinders would first strengthen and then weaken when the spacing between the two cylinders increases. Haider and Sohn [33] revealed the forces and amplitude have the minimum values then the spacing is $3.5 D$ for the two circular cylinders in tandem. The FIV of two cylinders in tandem for $30,000<R e<105,000$ is a numerical studied by Ding et al. [7]. The CFD (Computational Fluid Dynamics) results were well-matched with that of experimental tests and the maximum oscillatory amplitude of 3.5 diameters is obtained in galloping when $R e=105,000$. Lan et al. [34] discussed the instantaneous phase difference between the motion of the two cylinders in tandem and revealed three dominant patterns of oscillation for this case. Experimental investigation is conducted out by Qin et al. [35] to analyze the FIV response of two tandem cylinders with different natural frequencies. Both vortex-induced vibration and galloping may be suppressed at different reduced velocity ranges when the natural frequencies of the cylinders are different. In addition, the flow behind a flexible cylinder differs from the flow behind a rigid cylinder [36]. Therefore, the FIV responses of two flexible cylinders are quite different from that of the 
two rigid cylinders mounted on springs. Xu et al. [37] investigated the FIV of two flexible cylinders in tandem and found that, due to the vortices generated by the upstream cylinder, the response of the downstream cylinder obviously differs from the upstream one. Ma et al. [38] concluded that the upstream cylinder will influence FIV response of the downstream one and the effect is becoming more dominant as damping increases.

It should be pointed that few papers studied the disturbances among multiple cylinders $[39,40]$ and all of those cylinders are stationary. Kim and Bernitsas [41] experimentally studied the FIV of three cylinders in tandem. Various flow structures and transitions were observed. However, the details of the transition mechanism are difficult to be measured directly in the experiment, such as the near-wake structures, boundary layer, and characteristics of force on cylinders. Therefore, a series of numerical simulations are conducted in this work for a further understanding of the FIV of three cylinders in tandem, and the hydrokinetic energy harvesting of oscillation system in high density are discussed. The arrangement of this paper is as follows: Sections 2 and 3 illustrate the physical and numerical models; the VIV responses of the three cylinders are presented and discussed in Section 4, such as the results of amplitude, frequency, energy conversion, and vortex patterns; conclusions are drawn at the end.

\section{Physical Model}

The oscillatory system in the present work is three cylinders in tandem which is shown in Figure 1 . The system includes three identical cylinders with PTC, each one of the oscillatory cylinders consists of a circular cylinder of diameter $D$, stiffness $K$, and system damping $C$ for the exit of friction. The center-to-center distance, $\mathrm{d}$, between adjacent cylinders is fixed at 2.5D. And all of the three cylinders are limited to oscillate in the $y$-direction, thus perpendicular to the direction of the inlet velocity $U$. As previously mentioned, PTC that consist of the roughness strips are induced to enhance FIV of the circular cylinders. The geometrical characteristic and angle of the roughness strips are referred to in the previous studies of MRELab on the PTC $[6,10,12]$. As shown in Figure 1, there are two roughness strips arranged symmetrically in the surface of all cylinders. Geometrical characteristic of each strip is: $1.27 \mathrm{~cm}$ width and covers $16^{\circ}$ of the surface of circular cylinder with a diameter of $8.89 \mathrm{~cm}$. The placement of strips on the cylinder is $30^{\circ}$ from the front stagnation point when it is assumed that the fluid medium is ideal flow. The system parameters for the three cylinders with PTC are listed in Table 1.

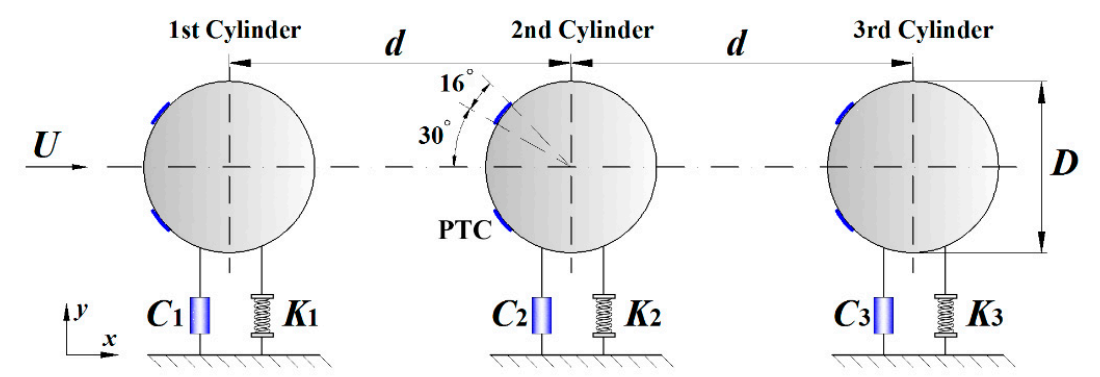

Figure 1. Physical model of three cylinder with roughness.

Table 1. Parameters of the three-cylinder oscillators.

\begin{tabular}{ccccc}
\hline Parameters & Symbol & 1st Cylinder & 2nd Cylinder & 3rd Cylinder \\
\hline Diameter & $D[\mathrm{~m}]$ & 0.0889 & 0.0889 & 0.0889 \\
Oscillating mass per unit length & $m[\mathrm{~kg}]$ & 10.42 & 10.49 & 10.40 \\
Spring stiffness per unit length & $\mathrm{K}[\mathrm{N} / \mathrm{m}]$ & 834 & 828 & 806 \\
Damping per unit length & $\mathrm{C}[\mathrm{N} \cdot \mathrm{s} / \mathrm{m}]$ & 3.79 & 3.70 & 3.15 \\
Damping ratio & $\zeta$ & 0.0206 & 0.0198 & 0.0172 \\
Mass ratio & $m^{*}$ & 1.681 & 1.690 & 1.667 \\
Natural frequency & $f_{n, \text { water }}[\mathrm{Hz}]$ & 1.114 & 1.121 & 1.109 \\
\hline
\end{tabular}




\section{Numerical Approach}

\subsection{Governing Equations and Integration Scheme}

In the present study, the flow around the three cylinders with PTC is studied by solving the 2D Unsteady Reynolds Averaged Navier-Stokes (URANS) equations together with the Spalart-Allmaras (S-A) turbulence model. Though the LES (Large Eddy Simulation) or DNS (Direct Numerical Simulation) study can get more accurate results [42], the application of the RANS model can save computational resources and obtain reasonable results. The governing equations are:

$$
\begin{gathered}
\partial U_{i} / \partial x_{i}=0 \\
\frac{\partial U_{i}}{\partial t}+\frac{\partial}{\partial x_{j}}\left(U_{i} U_{j}\right)=-\frac{1}{\rho} \frac{\partial p}{\partial x_{i}}+\frac{\partial}{\partial x_{j}}\left(2 v S_{i j}-\overline{u_{i}^{\prime} u_{j}^{\prime}}\right)
\end{gathered}
$$

where $x_{i}$ are the Cartesian coordinates, $U_{i}$ represent the corresponding velocity components, $v=\mu / \rho$ is the molecular kinematic viscosity which is a constant in this study, and $S_{i j}$ is the mean strain-rate tensor.

$$
S_{i j}=\frac{1}{2}\left(\frac{\partial U_{i}}{\partial x_{j}}+\frac{\partial U_{j}}{\partial x_{i}}\right)
$$

The Reynolds-stress tensor $\tau_{i j}=-\rho \overline{u_{i}^{\prime} u_{j}^{\prime}}$ can be modeled by the Boussinesq eddy-viscosity approximation as $2 \mu_{t} S_{i j}$, where $\mu_{t}$ means the turbulence eddy viscosity. In the standard S-A model [43], $\mu_{t}$ can be obtained from:

$$
\begin{gathered}
\mu_{t}=\rho \widetilde{v} f_{v 1} \\
f_{v 1}=\chi^{3} /\left(\chi^{3}+c_{v 1}^{3}\right) \\
\chi=\widetilde{v} / v
\end{gathered}
$$

$\widetilde{v}$ is an intermediate variable of S-A model. It obeys the following transport equation:

$$
\frac{\partial \widetilde{v}}{\partial t}+u_{j} \frac{\partial \widetilde{v}}{\partial x_{j}}=c_{b 1} \widetilde{S} \widetilde{v}-c_{w 1} f_{w}\left(\frac{\widetilde{v}}{d}\right)^{2}+\frac{1}{\sigma}\left\{\left[\frac{\partial}{\partial x_{j}}(\widetilde{v}+v) \frac{\partial \widetilde{v}}{\partial x_{j}}\right]+c_{b 2} \frac{\partial \widetilde{v}}{\partial x_{i}} \frac{\partial \widetilde{v}}{\partial x_{i}}\right\}
$$

The definitions of the functions and constants in S-A model are given by Spalart and Allmaras [43]. The trip terms $f_{t 1}$ and $f_{t 2}$ in the standard version of the Spalart-Allmaras model are turned off in this paper. And the "trip-less" initial condition [44] for $v_{t}$ and $v$, which was successfully used in earlier work [7], is adopted in this study.

Mathematically, the oscillatory system is assumed to be the mass-spring-damper system which is used to model the cylinder in FIV. The classic mathematic description of motion can be simplified as:

$$
m \ddot{y}+C_{\text {system }} \dot{y}+K y=F_{f l u i d, y}
$$

where $F_{f l u i d, y}$ is the fluid force acting on the cylinder.

For the divergence, gradient, and Laplacian terms in the governing equations, a second-order Gauss integration scheme is applied. For time integration, the second-order backward Euler method is used. Therefore, second order accuracy in space and time can be reached for the numerical discretization scheme in this study. The momentum and continuity equations are solved by PISO algorithm. PISO means a pressure implicit with splitting of operators. A second-order mixed implicit and explicit time integration scheme is adopted to solve the equation of motion for the cylinder.

The converted power by multiple cylinder is defined as:

$$
P_{\text {convert }}=\frac{1}{T_{\text {osc }}} \int_{0}^{T_{o s c}} F_{\text {fluid, }, y} y d t+\frac{1}{T_{o s c}} \int_{0}^{A_{\text {peaks }}} F_{k} d y
$$


where $T_{o s c}$ is the period of cylinders, and $F_{k}$ is elastic force, can be defined as:

$$
F_{k}=K y
$$

So we can calculate the converted power from Equations (8)-(10):

$$
P_{\text {convert }}=\frac{1}{T_{\text {osc }}} \int_{0}^{T_{\text {osc }}}\left(m \ddot{y}+C_{\text {system }} y+K y\right) \dot{y} d t+\frac{1}{T_{\text {osc }}} \int_{0}^{A_{\text {peaks }}} K y d y
$$

Assuming that the oscillation of a cylinder in FIV is sinusoidal, the amplitude and its differential can be written as:

$$
\left\{\begin{array}{l}
y=A_{\text {peaks }} \sin (w t)=A_{\text {peaks }} \sin \left(2 \pi f_{\text {osc }} t\right) \\
\dot{y}=2 \pi f_{\text {osc }} A_{\text {peaks }} \cos \left(2 \pi f_{\text {osc }} t\right) \\
\ddot{y}=-4 \pi^{2} f_{\text {osc }}^{2} A_{\text {peaks }} \sin \left(2 \pi f_{\text {osc }} t\right)
\end{array}\right.
$$

So, Equation (11) can be rewritten as:

$$
P_{\text {convert }}=P_{\text {mech }}+P_{k}=2 \pi^{2} f_{\text {osc }}^{2} A_{\text {peaks }}^{2} C_{\text {system }}+\frac{1}{2} K A_{\text {peaks }}^{2} f_{\text {osc }}
$$

The power in a fluid can be calculated through the area swept by the cylinders:

$$
P_{\text {fluid }}=\frac{1}{2} \rho U^{2}\left(2 A_{\text {peaks }}+D\right) L
$$

The converted efficiency is defined as:

$$
\eta_{\text {convert }}(\%)=\left(P_{\text {convert }} / P_{\text {fluid }}\right) \times 100
$$

\subsection{Computational Domain and Grid Generation}

The domain size is $55 D \times 9 D$ for the three cylinders system. As presented in Figure 2, five boundaries of the entire domain are: inflow boundary, outflow boundary, bottom wall, top wall, and the cylinders. The initial positions of the three cylinders, which are also the neutral positions, are located at the center of the domain in the vertical direction. The size between the inflow boundary and the center of the first cylinder, $l_{u p}$ is $25 D$. The length of the downstream domain, $l_{\text {down }}$ is also $25 D$. This is to ensure that the results of the CFD model are accurate. Meanwhile, the conditions at the outflow are close to the assumed conditions. As the water depth of the experiment [41] is $0.8 \mathrm{~m}$, which is equal to $9 D$, the domain size in $y$-direction is considered as $9 D$ in the simulation.

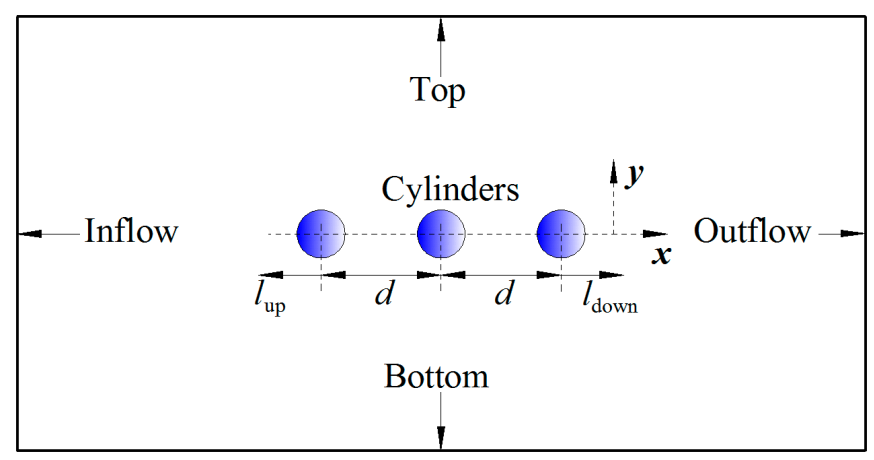

Figure 2. Computational domain.

An inflow with uniform and constant velocity is defined for the inlet boundary. In order to have negligible influence on the near-wake flow, the zero gradient condition is specified for velocity at the outflow boundary. And the specification of the outflow condition is justified because $l_{\text {down }}$ 
is sufficiently long. The top and bottom conditions are considered as wall boundary to match the experimental set. The moving wall conditions are used for the three cylinders in FIV. A wall function is applied to account for the effect of the surface roughness for the PTC.

The structured mesh was generated for the simulations of the three PTC-cylinders in this work. In numerical studies on the cylinder in FIV, large mesh deformation occurs when the cylinder undergoes galloping. In order to minimize the mesh motion, a topological dynamic mesh technique is applied. A square subdomain $(2 D \times 2 D$ in this cases) for the near-wall region of each cylinder was plotted. This subdomain vibrates in vertical direction with the cylinder in FIV. During the simulation, the layers near the top and bottom of the subdomain will be removed or generated. A detailed explanation for the dynamic mesh technique can be found in the work by Ding et al. [7]. The grid independence study was conducted to find a suitable mesh for the calculations of three cylinders in FIV. Three different grid densities were studied and compared. Depending on Re, the near-wall grid size was chosen to produce a $y$-plus between 30 and 70 . The grid parameters and the results are listed in Table 2. The different grid densities result in similar values about the drag coefficient $\left(C_{D}\right)$, lift coefficient $\left(C_{L}\right)$, and Strouhal number $\left(S_{t}\right)$ of the three cylinders. Thus, the medium grid resolution was selected for simulations of the three cylinders in this work. The cropped view of the medium grid for the cylinders at rest is shown in Figure 3a. And Figure $3 b$ shows the grid near the cylinders when the three cylinders are in FIV.

Table 2. Grid resolution study $\left(R e=3 \times 10^{4}\right)$.

\begin{tabular}{cccccccccc}
\hline \multirow{2}{*}{ Grid (Central Square) } & \multicolumn{3}{c}{$C_{\boldsymbol{D}}$} & \multicolumn{4}{c}{$C_{\boldsymbol{L}}$} & \multicolumn{3}{c}{$S_{\boldsymbol{t}}$} \\
\cline { 2 - 11 } & 1st & 2nd & 3rd & 1st & 2nd & 3rd & 1st & 2nd & 3rd \\
\hline Coarse $(180 \times 40)$ & 1.29 & 0.525 & 0.15 & 1.499 & 1.635 & 1.095 & 0.213 & 0.213 & 0.214 \\
Medium $(240 \times 70)$ & 1.283 & 0.522 & 0.149 & 1.501 & 1.66 & 1.109 & 0.213 & 0.213 & 0.213 \\
Fine $(360 \times 100)$ & 1.282 & 0.523 & 0.147 & 1.505 & 1.657 & 1.106 & 0.213 & 0.213 & 0.213 \\
\hline
\end{tabular}

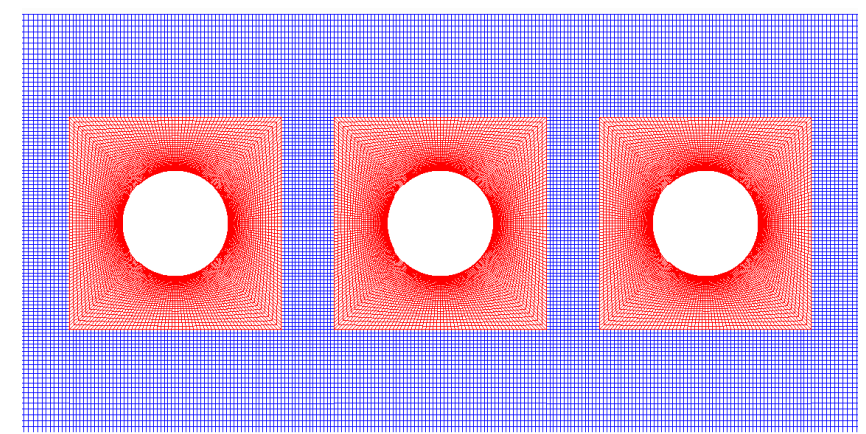

(a)

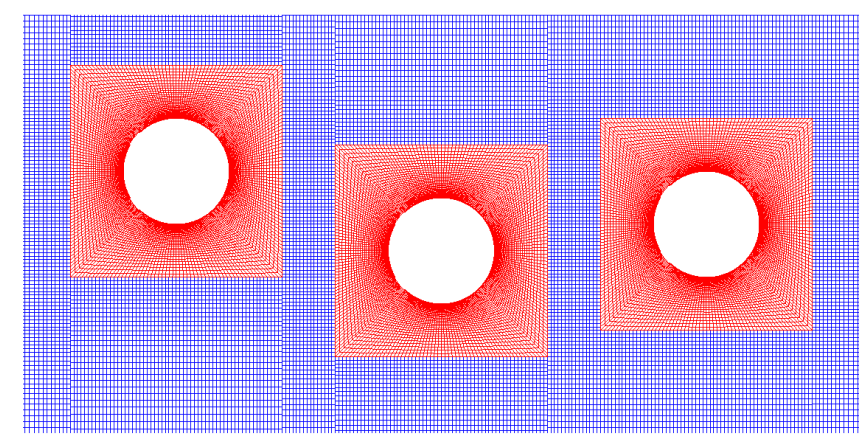

(b)

Figure 3. Topological change of dynamic mesh. (a) original mesh, (b) cylinders in FIV 


\section{Results and Discussion}

A series of simulations were conducted to predict the FIV response and energy harvesting of three PTC-cylinders using 2D-URANS. The range of Reynolds numbers is 30,000 $<R e<105,000$. It falls in the high-lift TrSL3 regime. TrSL3 stands for the third region of Transition in Shear Layer [45]. And the corresponding reduced velocity $\left(U_{\text {water }}^{*}=U /\left(f_{n \text {,water }} D\right)\right)$ range is $3.85<U_{\text {water }}^{*}<13.49$. The free stream velocity range is $0.38 \mathrm{~m} / \mathrm{s} \leq U \leq 1.35 \mathrm{~m} / \mathrm{s}$. In addition, the inherent frequency of the first cylinder is employed to calculate the reduced velocity in this paper. For all three cylinders, the velocity and the displacement are equal to zero in the initial position when $t=0 \mathrm{~s}$. In this section, the following aspects are presented: the amplitude and frequency responses, the convert power, and conversion efficiency of the three PTC-cylinders. To verify the accuracy of the simulation, the simulated results is compared with the experiments of Kim and Bernitsas [41]. The experiment which was used to obtain the reference data was conducted in low turbulence free surface water channel. The conditions of a turbulent channel have a significant impact on the experimental results [46]. The test section of this channel is $2.44 \mathrm{~m}$ long, $1 \mathrm{~m}$ wide, and $0.8 \mathrm{~m}$ deep. And the turbulence intensity normalized by the flow velocity was $0.095 \%$. In order to thoroughly understand the FIV driving mechanisms of the three cylinders, the near-wake structures under typical Reynolds numbers are discussed as well.

\subsection{Amplitude Responses of Three Cylinders}

The amplitude of the cylinder is one of the key properties which can effectively describe and quantify FIV. The amplitude ratios $A_{\text {peaks }} / D$ of the three PTC-cylinders are plotted in Figure 4 . As shown in Figure 4, four branches can be captured in the curve of amplitude response, namely the initial branch of vortex-induced vibration, the upper branch, transition regime from VIV to galloping, and galloping branch.

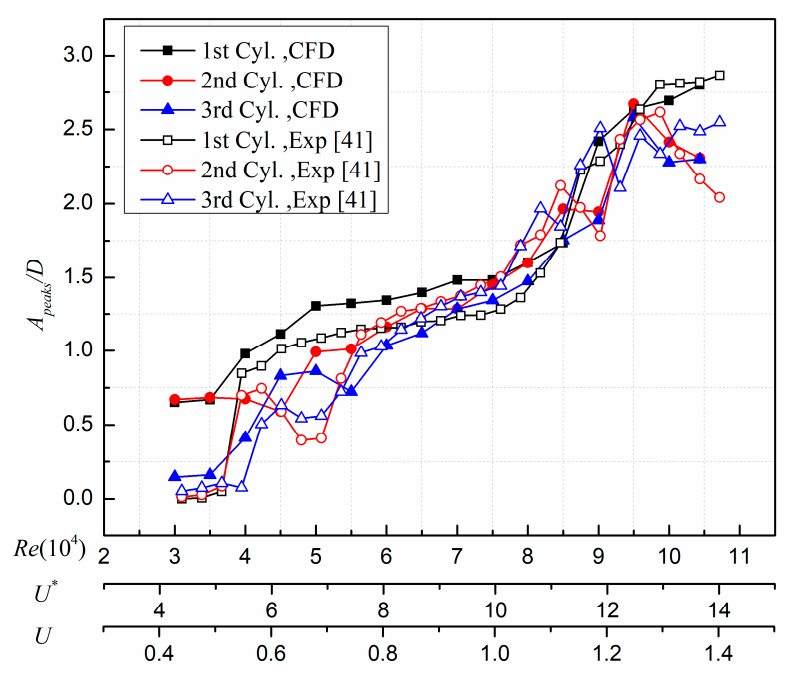

Figure 4. Amplitude responses of three cylinders in flow-induced vibration (FIV).

(a) The VIV initial branch: For the first cylinder in simulation, the initial branch is initiated at Reynolds numbers of $30,000\left(U_{\text {water }}^{*}=3.85\right)$, and the branch range is $30,000 \leq R e<40,000$ $\left(3.85 \leq U_{\text {water }}^{*}<5.14\right)$. However, the vibration of the first cylinder in experiment of Kim and Bernitsas [41] is not excited in this branch. For the second cylinder, the amplitude ratios in the VIV initial branch are close to that of the first cylinder around $R e=30,000\left(U_{\text {water }}^{*}=3.85\right)$. And the amplitude of the second cylinder in the experiment is still lower than that of the simulation in the initial branch. In addition, the motion of the third cylinder is severely disturbed by the first and second cylinders. The amplitude response for the third cylinder in simulation is only $0.15 D$ at $R e=30,000\left(U_{\text {water }}^{*}=3.85\right)$. And in the experiment, the FIV of the third cylinder is almost 
suppressed and the amplitude is $0.05 D$ at $R e=30,000\left(U_{\text {water }}^{*}=3.85\right)$. The reason for the low amplitude ratio of the third cylinder is that the formation of vortices behind the third cylinder is suppressed, which is further explained in Section 4.5.

(b) The VIV upper branch: 40,000 $\leq \operatorname{Re}<85,000\left(5.14 \leq U_{\text {water }}^{*}<10.92\right)$ is the upper branch for the first cylinder. The simulations show that the amplitude of the first cylinder increases steadily as the velocity increases and the amplitude ratio rises from 0.98 to 1.74 in the VIV upper branch. Due to the existence of the upstream cylinder, the VIV upper branches of the second and third cylinder are initiated at $R e=50,000\left(U_{\text {water }}^{*}=6.43\right)$ and $R e=45,000\left(U_{\text {water }}^{*}=5.78\right)$, respectively. The motions of the downstream cylinders are influenced by the vortex from the first cylinder. Specifically, a drop in the amplitude of the third cylinder at $R e=55,000\left(U_{\text {water }}^{*}=7.07\right)$ can be observed in simulation.

(c) Transition regime from VIV to galloping: a rapid rise of amplitude for the first cylinder at $85,000 \leq R e<95,000\left(10.92 \leq U_{\text {water }}^{*}<12.21\right)$ can be obtained both in the simulation and experimental test. The transition from VIV to galloping occurs at $U_{\text {water }}^{*}=10.92$ for the cylinder with PTC. But for the downstream two cylinders, the VIV upper branch collapses onto galloping without significant demarcation. The amplitude response of the second cylinder fluctuates in this region and the amplitude ratio increases from 1.96 to 2.67 .

(d) Galloping region: For $R e \geq 95,000\left(U_{\text {water }}^{*} \geq 12.21\right)$, galloping initiated and the maximum value of $2.8 D$ is reached by the first cylinder. It is worthwhile noting that $2.8 D$ is the limit of the experimental water channel, and the limit is considered as $2.8 D$ in the present simulations as well. Due to the effect of the upstream cylinder, the amplitude ratios of the downstream cylinder are smaller than the upstream one. For the second cylinder, the amplitude decreases in the galloping branch both in CFD and experiment. The vortices which generate from the first cylinder attach on to the second cylinder. This phenomenon results in the reduction of lift force on the second cylinder. Further, the amplitude of the second cylinder decreases in the galloping branch. In addition, the amplitude of the third cylinder stays around $2.3 \mathrm{D}$ in the galloping region.

\subsection{Frequency Responses of Three Cylinders}

The oscillation frequency of the cylinder is calculated by Fast-Fourier-Transform over the recorded displacement history of the cylinder. The dominant frequency $f_{o s c}$ is non-dimensionalized by the natural frequency $f_{n \text {,water }}$ of the first cylinder. As shown in Figure 5 , the frequency ratios $f_{\text {osc }} / f_{n, \text { water }}$ of the three PTC-cylinders are plotted as the function of Reynolds number $R e$, reduced velocity $U_{\text {water, }}^{*}$ and flow velocity $U$. In the simulation, the frequency increases during the VIV initial branch for the first and third cylinders. But for the second cylinder, the frequency encounters a drop-off at $R e=40,000\left(U_{\text {water }}^{*}=5.14\right)$. The major harmonic frequencies of the three cylinders in initial branch are higher in CFD results than that of experiments. And a large jump of the frequency is observed in the experiments around $R e=40,000\left(U_{\text {water }}^{*}=5.14\right)$. When the oscillation mode switches to the upper branch of VIV, the frequency ratio of the first cylinder decreases with increasing of Re in the simulation. After $R e=50,000\left(U_{\text {water }}^{*}=6.43\right)$, frequency ratio stabilizes near 1.10 in the VIV upper branch for the three PTC-cylinders. As Re increases from $70,000\left(U_{\text {water }}^{*}=9.00\right)$ to 80,000 $\left(U_{\text {water }}^{*}=10.28\right)$, the frequency ratio of the first cylinder increases from 1.10 and reaches a maximum value of 1.21. Contrarily, the frequency of the second cylinder has a slight decrease in this region. As the velocity goes up, there is a decrease in frequency of the first cylinder matching the large jump of the amplitude around $R e=90,000\left(U^{*}\right.$ water $\left.=11.57\right)$, which indicates the oscillation of the first cylinder transits from VIV upper branch to galloping. Galloping is known to be a low frequency and high amplitude oscillation [6,23]. In the galloping branch ( $\left.R e \geq 95,000, U_{\text {water }}^{*} \geq 12.21\right)$, the frequencies of the three PTC-cylinders are close and stable around the natural frequency. It should be noted that the amplitude and frequency results show the back-to-back VIV and galloping for the three cylinders in tandem. The key factor in observing this behavior is the application of PTC on the cylinders [7,12]. 


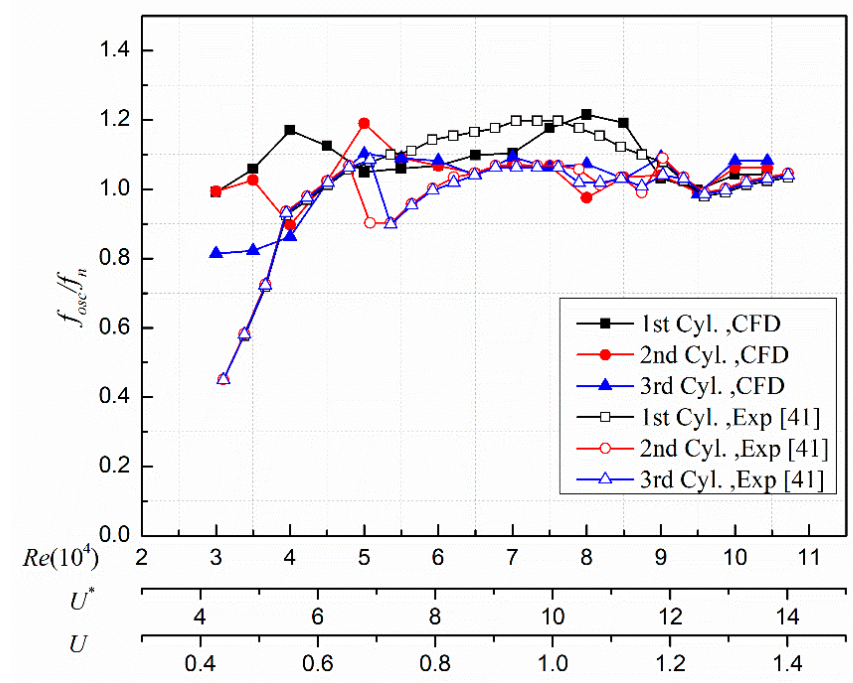

Figure 5. Frequency responses of three cylinders in FIV.

As shown in Figures 4 and 5, the mainly deviations of FIV responses between simulation and experiment appear in the VIV initial branch. This is attributed to the difference between the damping model in CFD and the actual model in experiment. In this paper, the damping of the oscillating system is considered as linear viscous damping. The linear viscous model can be acceptable when the velocity of the oscillator is relatively high and response is near resonance. This model can match well with the experiment in most branches of FIV. However, when oscillations are away from resonance, the viscous model is no longer linear. Therefore, the deviation is obvious in the initial branch.

\subsection{Converted Power}

The total converted power of the multiple cylinders is the sum of that for each cylinder, which can be expressed as

$$
P_{\text {convert }}=\sum_{i=1}^{n} P_{\text {convert }, n}
$$

Figure 6 depicts the power of the system for three cylinders varies with the velocity and compared with the power by the single cylinder and two cylinders. As shown in Figure 6, the converted power $P_{\text {convert }}$ increases with the increase of $U_{\text {water }}^{*}$, for all case. And the converted power increases slowly when $\operatorname{Re}<80,000\left(U_{\text {water }}^{*}=10.28\right)$. For the results of single cylinder [47], the converted power of single cylinder does not increase too much with the rise of $R e$. The maximum value of converted power for this case is $24.1 \mathrm{~W}$. The converted power of two cylinders in tandem rise rapidly after $R e=80,000$ $\left(U_{\text {water }}^{*}=10.28\right)$, the maximum value is $69.97 \mathrm{~W}$ when $R e=101,500\left(U_{\text {water }}^{*}=13.40\right)$. While the $R e$ increases from $55,000\left(U_{\text {water }}^{*}=7.07\right)$ to $105,000\left(U_{\text {water }}^{*}=13.50\right)$, the growth of the converted power in the experiments is rapider than the power converted by the three cylinders in the numerical results. The present result shows that the converted power is monotone increasing from $1.41 \mathrm{~W}$ to $88.68 \mathrm{~W}$ when $30,000 \leq \operatorname{Re}<95,000\left(3.85 \leq U^{*}\right.$ water $\left.<12.21\right)$, and then decline to $85.26 \mathrm{~W}$ in the range of $95,000 \leq \operatorname{Re}<105,000\left(12.21 \leq U^{*}\right.$ water $\left.<13.48\right)$. For the experiment, the power increases slowly by Re increases from 30,000 to $45,000\left(3.85 \leq U^{*}\right.$ water $\left.<5.81\right)$, and it sharply increases from $24.29 \mathrm{~W}$ to $94 \mathrm{~W}$ in the range of $45,000 \leq \operatorname{Re}<95,000\left(5.81 \leq U_{\text {water }}^{*}<12.21\right)$. And the maximum power is achieved at $94 \mathrm{~W}$ and $85.26 \mathrm{~W}$ in the experiment and simulation, respectively. 


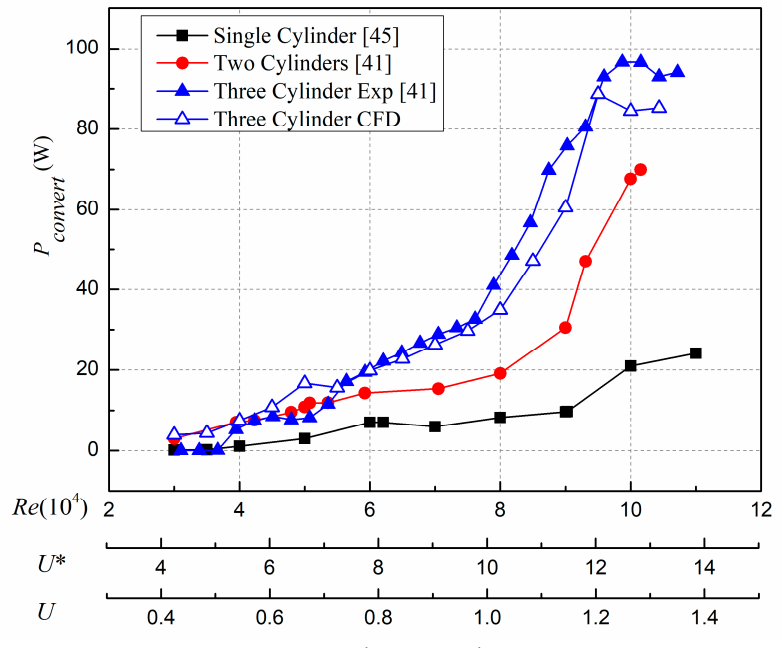

Figure 6. Total power harvesting.

\subsection{Energy Conversion Efficiency}

Figure 7 presents the energy conversion efficiency of FIV for single cylinder, two cylinders in tandem, three cylinders in experiment and simulation. The overall trends of energy conversion efficiency are similar for each test. Firstly, the energy conversion efficiency increases from $5.45 \mathrm{~W}$ to $33.85 \mathrm{~W}$ when $30,000 \leq \operatorname{Re}<60,000\left(3.85 \leq U^{*}\right.$ water $\left.<7.70\right)$ and then decline for the single cylinder. In terms of two cylinders in tandem, the energy conversion efficiency rises rapidly for $30,000 \leq R e<50,500\left(3.85 \leq U_{\text {water }}^{*}<6.48\right)$ and then a sharp decrease in the range of $50,500 \leq \operatorname{Re}<59,000\left(6.48 \leq U_{\text {water }}^{*}<7.57\right)$, then a gradual decline after $R e=59,000\left(U_{\text {water }}^{*}=7.57\right)$. The maximum energy conversion efficiency of two cylinders in tandem is $34.10 \mathrm{~W}$ when $R e=55,500$ $\left(U_{\text {water }}^{*}=6.48\right)$. In the numerical results of three cylinders, the energy conversion efficiency of the three cylinders system increases maximum and then decreases with increasing Reynolds numbers. In the range of $40,000 \leq R e<50,000\left(5.14 \leq U_{\text {water }}^{*}<6.43\right)$, which correspond to the starting region of the VIV upper branch, the energy conversion efficiency is stable and higher than $35 \%$ for the three cylinders. And the maximum value is reached at $40.41 \%$ when $R e=40,000\left(U_{\text {water }}^{*}=5.14\right)$. However, two peaks of the energy conversion efficiency are observed for the three cylinders system in the experiments. When $R e$ increases from 30,000 to 42,300 ( $3.85 \leq U^{*}$ water $\left.<5.43\right)$, the conversion efficiency rises continually and the maximum efficiency $37.76 \%$ is obtained at $R e=42,300$ ( $U_{\text {water }}^{*}=5.43$ ). In the range $42,300 \leq R e<56,400\left(5.43 \leq U_{\text {water }}^{*}<7.24\right)$, the efficiency decreases firstly, then increases again. And a local peak $31.39 \%$ is received when $R e=56,400\left(U_{\text {water }}^{*}=7.24\right)$ in the experiments. After $R e \geq 56,400$ ( $U_{\text {water }}^{*} \geq 7.24$ ), the efficiency is slowly decline from $31.39 \%$ to $12.17 \%$.

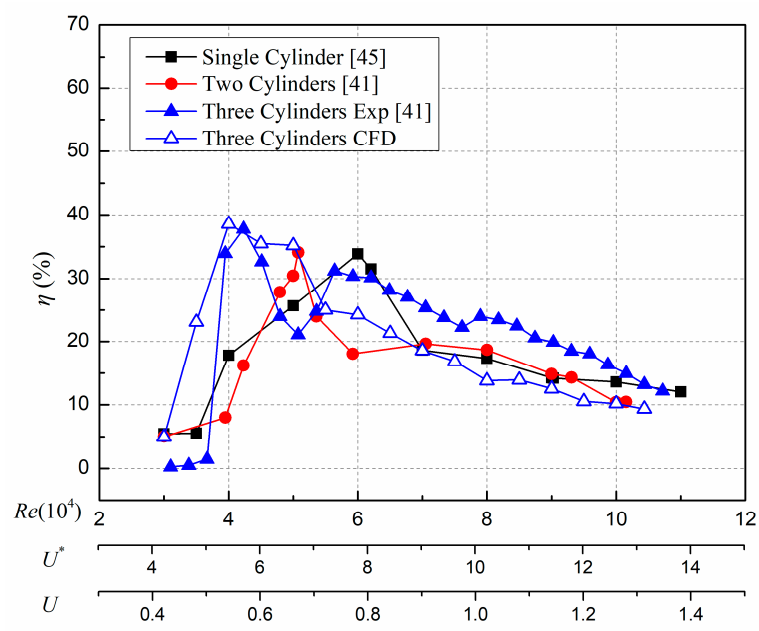

Figure 7. Power conversion efficiency. 


\subsection{Near-Wake Structure}

Compared with the experiment, the visualization of the near-wake structures can be obtained by numerical simulation, which can be helpful to understand the vortex dynamics and useful to illustrate the complex motion status of multiple cylinders at high Reynolds numbers. There are certain forms of the vortex pattern related to FIV [48], such as $2 \mathrm{~S}, 2 \mathrm{P}$, and $2 \mathrm{P}+2 \mathrm{~S}$. " $\mathrm{S}$ " and " $\mathrm{P}$ " stand for single and pair of vortices, respectively. The shape of any amplitude curve is closely related to the vortex pattern throughout the FIV branches [7,49]. The near-wake structures of the three PTC-cylinders in FIV at four typical Reynolds numbers which correspond to different FIV branches are presented and discussed in this section.

\subsubsection{VIV Initial Branch}

The vortex patterns of the three cylinders at $R e=30,000\left(U_{\text {water }}^{*}=3.85\right)$ are shown in Figure 8 . And the displacement time histories for each cylinder are shown in Figure 9. The FIV of the cylinders are in initial branch. Note that the times in the figures of vortex structures are non-dimensionalized by the natural period $T_{n}$ of the first cylinder. As shown in Figure 8, two vortices are shed from the first cylinder in one period of oscillation. The vortex pattern is the typical $2 \mathrm{~S}$ mode. For the second cylinder, the body moves through the gap between the vortices shedding from the first cylinder. The vortex formation behind the second cylinder is affected by the vortices of first cylinder, but the shear layers separate successfully. Thus, the lift force on the second cylinder changes periodically and the maximum displacement of the second cylinder is close to the first cylinder (see Figure 9a,b). However, the vortex shedding is hardly observed for the third cylinder. The third cylinder locates in the wake of the upstream two cylinders, the vortices from the first and second cylinders prevent the formation of vortices behind the third one. The motion of the third cylinder is suppressed in some cycles and the displacement is very small, which can be clearly observed in Figure 9c.
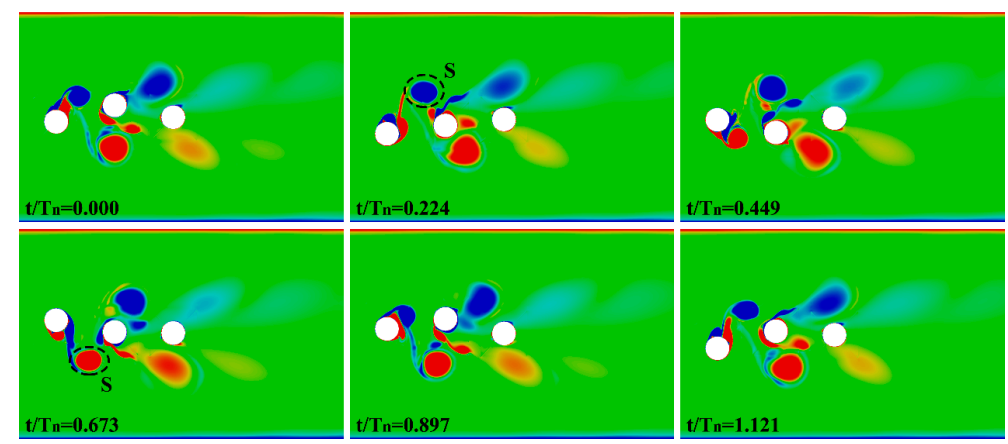

Figure 8. Near-wake structure of the three cylinders when $R e=30,000$.
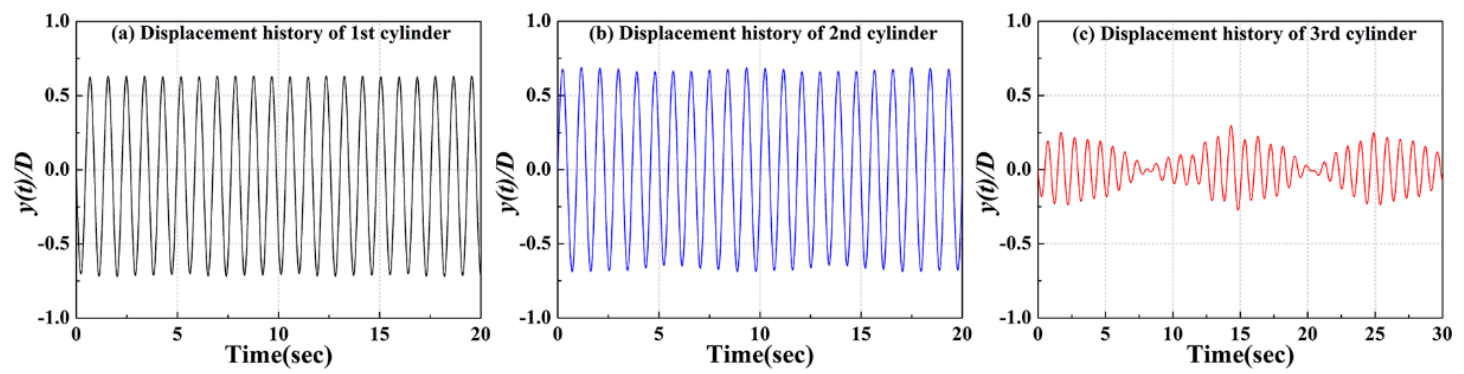

Figure 9. Time history curves of displacement for three cylinders when $R e=30,000$.

\subsubsection{VIV Upper Branch}

As $R e$ increases, the oscillation mode of the cylinders transits from the initial branch to the upper branch. For $R e=60,000\left(U^{*}\right.$ water $\left.=7.71\right)$, the three cylinders oscillate in the upper branch. The near-wake 
vortex structures are illustrated in Figure 10. For the first cylinder, four vortices are shed per cycle of oscillation and the vortex pattern is $2 \mathrm{P}$. The vortex patterns of the second and third cylinders are not easy to identify as the vortices formation are disrupted by the shedding vortex associated with the first cylinder. It should be noted that the FIV of the downstream cylinder is stimulated by the alternating vortices shed from the upstream cylinder at $R e=60,000\left(U^{*}\right.$ water $\left.=7.71\right)$. That means the influence of the upstream cylinder on the oscillation of the downstream cylinder in upper branch is different with the suppression results of initial branch. Therefore, the amplitude responses of the second and third cylinders are excited to significant amplitudes. Figure 11 shows the displacement time history of each cylinder when $R e=60,000$ ( $\left.U_{\text {water }}^{*}=7.71\right)$. Although the motions of the second and third cylinders are affected by the first cylinder, the maximum displacements of the three cylinders are larger than $1 D$.
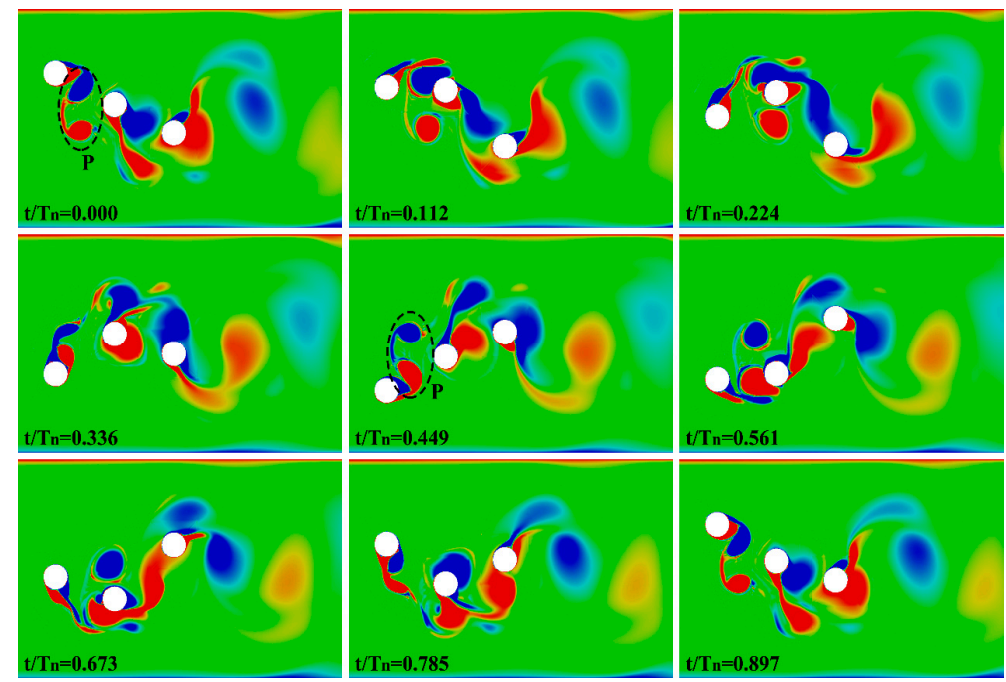

Figure 10. Near-wake structure of the three cylinders when $R e=60,000$.
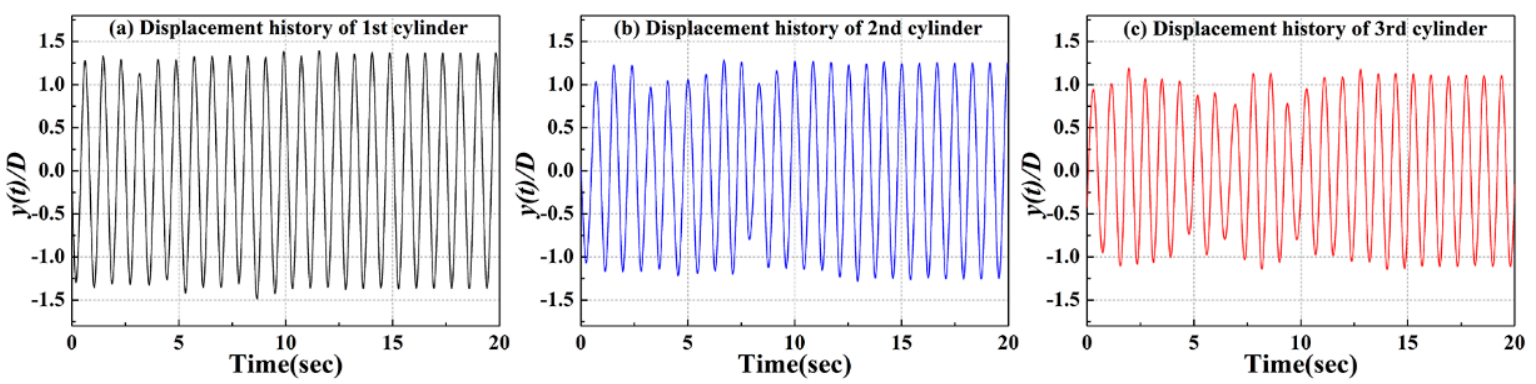

Figure 11. Time history curves of displacement for three cylinders when $R e=60,000$.

\subsubsection{VIV to Galloping Transition}

The transition from the VIV to galloping of the three PTC-cylinders starts when $R e=85,000$ $\left(U_{\text {water }}^{*}=10.92\right)$. There are two driving mechanisms coexist in this region: the wake pattern frequency lock-in and the galloping instability [7]. When $R e=90,000\left(U_{\text {water }}^{*}=11.57\right)$, the cylinders are in the transition region. It can be clearly observed that eight vortices shed from the first cylinder in one oscillation period in Figure 12. A pair (P) of vortices generate in the downward journey $\left(t / T_{n}=0.000-0.224\right)$ of the first cylinder. And a single vortex (S) is captured as the first cylinder further moving down. Another single vortex sheds when the first cylinder reaches the maximum displacement at $t / T_{n}=0.449$ in Figure 12. The ordering of the vortex shedding in the downward journey is $\mathrm{P}+\mathrm{S}+\mathrm{S}$ for the first PTC-cylinder. In the upward journey of the first cylinder $\left(t / T_{n}=0.561-0.897\right)$, the vortex shedding is $\mathrm{P}+\mathrm{S}+\mathrm{S}$ as well. Thus, the vortex pattern for the first cylinder is $2 \mathrm{P}+4 \mathrm{~S}$. For the second cylinder, the amplitude is smaller than the first cylinder (see in Figure 13) and six vortices 
can be captured in one oscillation period. The vortex pattern is $2 \mathrm{P}+2 \mathrm{~S}$ for the second $\mathrm{PTC}$-cylinder. In addition, the vortex formation of the third cylinder is disrupted and modified by the vortices from upstream cylinders. The vortex pattern for the third cylinder is hard to identify. The displacement time history of the three PTC-cylinders at $R e=90,000\left(U_{\text {woater }}^{*}=11.57\right)$ is shown in Figure 13 . The amplitude of the first cylinder is higher than the second and third cylinders. The maximum displacement reaches $2.7 D$ for the first cylinder.

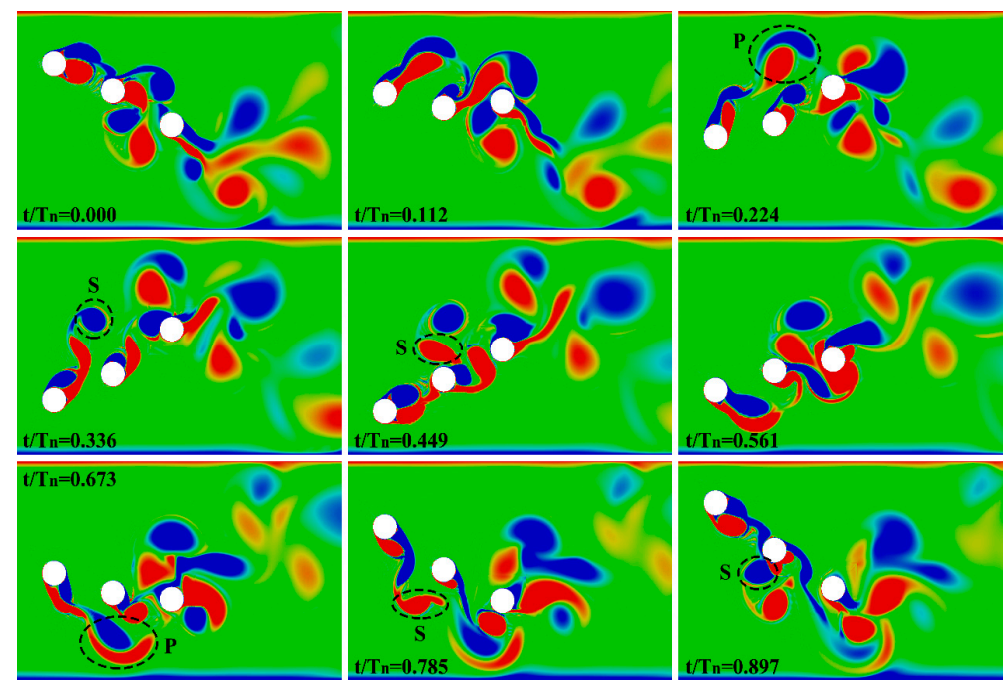

Figure 12. Near-wake structure of the three cylinders when $R e=90,000$.
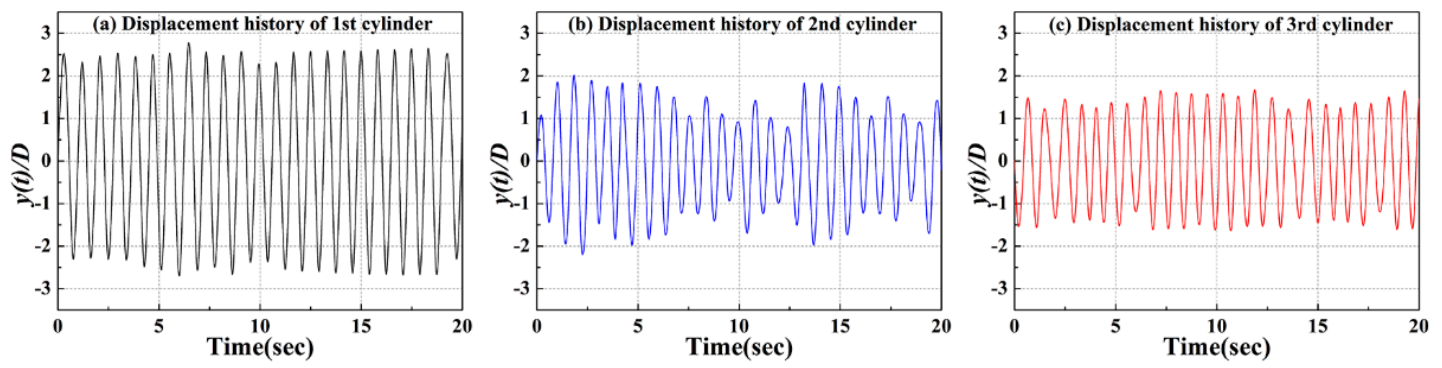

Figure 13. Time history curves of displacement for three cylinders when $\operatorname{Re}=90,000$.

\subsubsection{Fully Development Galloping}

Figure 14 presents the near-wake structures for the three PTC-cylinders in fully developed galloping when $R e=100,000\left(U_{\text {water }}^{*}=12.85\right)$. The FIV mode transition between branches is always accompanied by vortex structure changes [48,49]. Moreover, as the motion of the cylinder transits from VIV to galloping, the hydrodynamic driving mechanism changes [7]. The driving mechanism of galloping is no longer dependent on the vortex-induced force due to the vortex shedding. As shown in Figure 14, during the formation of vortices for the first cylinder, the shear layer moves follow the cylinder vibrations. The amplitude of the first cylinder is higher than $2.5 D$ (see in Figure 15a) and many vortices shed per period leading to more complex vortex patterns. The frequency of vortex shedding pattern does not match with the cylinder vibration in galloping. The driving mechanism of galloping is the instability of the lift due to the negative damping caused by the geometric asymmetry of the PTC-cylinder. The vortex pattern is $2 \mathrm{P}+6 \mathrm{~S}$ for the first cylinder at $R e=100,000\left(U_{\text {water }}^{*}=12.85\right)$. For the second cylinder, the vortex shedding is not only influenced by the vortices from the first cylinder but also disrupted by the motion of the third cylinder, which can be observed at $t / T_{n}=0.449-0.673$ in Figure 14. The shedding vortices from the second cylinder are disturbed even broken by the third cylinder. And then the vortex-induced force of second cylinder is influenced. The motions of the 
downstream PTC-cylinders are weakened by the upstream vortices. Thus, the amplitude ratios of the second and third cylinders reduce in some cycles as shown in Figure 15.
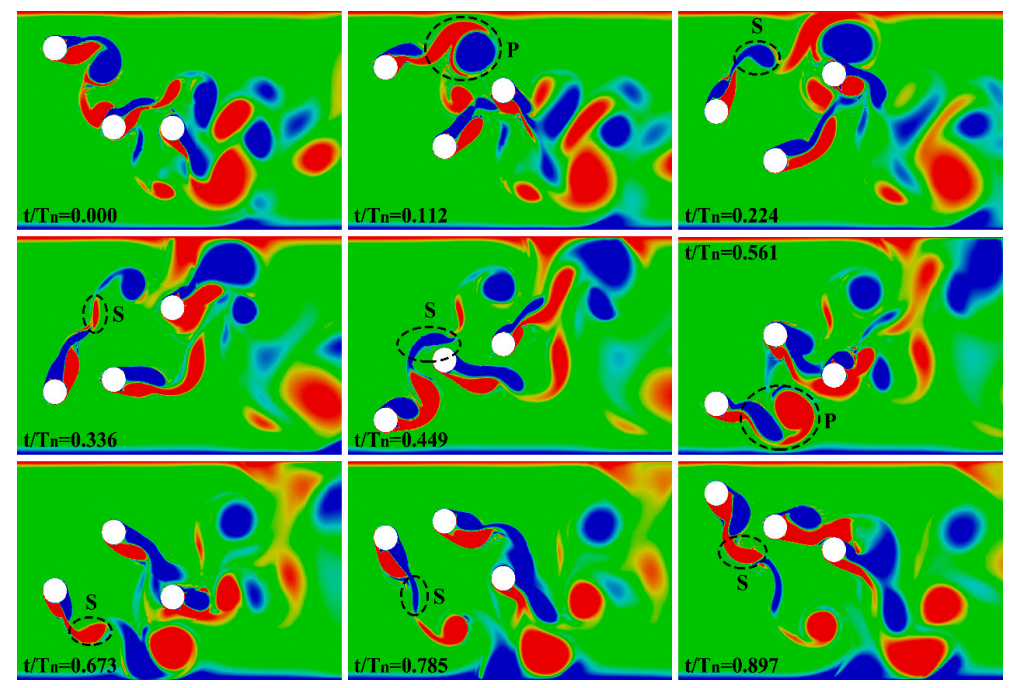

Figure 14. Near-wake structure of the three cylinders when $R e=100,000$.
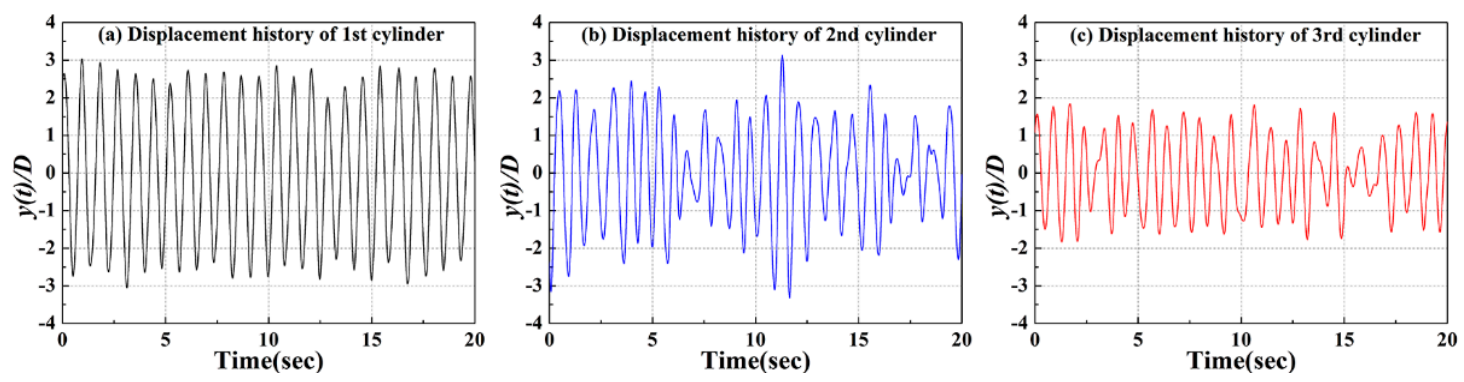

Figure 15. Time history curves of displacement for three cylinders when $R e=100,000$.

\section{Conclusions}

The FIV and energy harvesting of three circular cylinders with PTC in tandem were numerically investigated at 30,000 $\leq R e \leq 105,000$. And the corresponding velocity range of ocean and river currents is $0.38 \mathrm{~m} / \mathrm{s} \leq U \leq 1.35 \mathrm{~m} / \mathrm{s}$. The amplitude and frequency responses of three cylinders were presented and discussed. The converted power and energy conversion efficiency were also analyzed. The near-wake structures of three cylinders in each FIV branch were illustrated. Passive turbulence control was applied for enhancing the motion of all three cylinders in this research. It was proven to be a key factor in obtaining back-to-back VIV and galloping. The following conclusions can be drawn.

(1) Four branches of FIV can be clearly captured in the amplitude and frequency ratio curves of the three cylinders, including VIV initial branch, VIV upper branch, transition from VIV to galloping, and galloping. In the fully-developed galloping branch, a maximum displacement of $2.80 \mathrm{D}$ is reached by the first cylinder. And the frequency response varies with switching of FIV branches.

(2) The total converted power of the three cylinders increases with the increase of Reynolds number, and the maximum power is achieved at $85.26 \mathrm{~W}$. The energy conversion efficiency is stable and higher than $35 \%$ for the three cylinders in VIV when the inflow velocity is in the starting region of upper branch. And the maximum value of the efficiency is reached up to $40.41 \%$ when $R e=40,000$.

(3) The vortices shed from downstream cylinder are strongly disrupted and modified by the shedding vortices of the upstream cylinder. For VIV initial branch, vortex pattern $2 \mathrm{~S}$ is captured for the first cylinder and motion of the third cylinder is almost suppressed. And a $2 \mathrm{P}$ vortex pattern 
is observed for the first cylinder in the VIV upper branch. In the transition regime from VIV to galloping, the vortex patterns of the first and second cylinders are $2 \mathrm{P}+4 \mathrm{~S}$ and $2 \mathrm{P}+2 \mathrm{~S}$, respectively.

(4) The shear layer motion is synchronized with the motion of the cylinder in galloping. The galloping driving mechanism of the cylinder is the instability of the lift due to the negative damping caused by the geometric asymmetry of the PTC-cylinder.

Author Contributions: Conceptualization, L.D.; methodology, L.D.; software, L.D. and Q.Z.; validation, L.D. and Q.Z.; formal analysis, L.D. and Q.Z.; investigation, Q.Z.; resources, L.D. and L.Z.; data curation, L.D. and Q.Z.; writing-original draft preparation, L.D. and Q.Z.; writing-review and editing, L.Z. and H.W.; visualization, H.W.; supervision, L.Z.; project administration, L.D.; funding acquisition, L.D.

Funding: This research was funded by the National Natural Science Foundation of China, grant number 51776021; Natural Science Foundation of Chongqing, grant number cstc2016jcyjA0255; Fundamental Research Funds for the Central Universities, grant number 106112016CDJXY145505.

Conflicts of Interest: The authors declare no conflict of interest.

\section{References}

1. Narendran, K.; Guan, M.Z.; Ma, P.F.; Choudhary, A.; Hussain, A.A.; Jaiman, R.K. Control of vortex-induced motion in multi-column offshore platform by near-wake jets. Comput. Fluids 2018, 167, 111-128. [CrossRef]

2. Kumar, N.; Kolahalam, V.K.V.; Kantharaj, M.; Manda, S. Suppression of vortex-induced vibrations using flexible shrouding-An experimental study. J. Fluid Struct. 2018, 81, 479-491. [CrossRef]

3. Cachafeiro, H.; Arevalo, L.F.d.; Vinuesa, R.; Lopez-Vizcaino, R.; Luna, M. Analysis of Vacuum Evolution Inside Solar Receiver Tubes. Energy Procedia 2015, 69, 289-298. [CrossRef]

4. Bernitsas, M.M.; Raghavan, K.; Ben-Simon, Y.; Garcia, E.M.H. VIVACE (vortex induced vibration aquatic clean energy): A new concept in generation of clean and renewable energy from fluid flow. J. Offshore Mech. Arct. Eng. 2008, 130, 1-15. [CrossRef]

5. Rostami, A.B.; Armandei, M. Renewable energy harvesting by vortex-induced motions: Review and benchmarking of technologies. Renw. Sustain. Energy Rev. 2017, 70, 193-214. [CrossRef]

6. Kumar, R.A.; Bernitsas, M.M. VIV and galloping of single circular cylinder with surface roughness at $3.0 \times 10^{4} \leq \operatorname{Re} \leq 1.2 \times 10^{5}$. Ocean. Eng. 2011, 38, 1713-1732.

7. Ding, L.; Bernitsas, M.M.; Kim, E.S. 2-D URANS vs. experiments of flow induced motions of two circular cylinders in tandem with passive turbulence control for 30,000. Ocean. Eng. 2013, 72, 429-440. [CrossRef]

8. Zhang, J.; Liu, F.; Lian, J.J.; Yan, X.; Ren, Q.C. Flow Induced Vibration and Energy Extraction of an Equilateral Triangle Prism at Different System Damping Ratios. Energies 2016, 9, 22. [CrossRef]

9. Chandran, V.; M., S.; Janardhanan, S.; Menon, V. Numerical Study on the Influence of Mass and Stiffness Ratios on the Vortex Induced Motion of an Elastically Mounted Cylinder for Harnessing Power. Energies 2018, 11, 2580. [CrossRef]

10. Chang, C.C. Hydrokinetic Energy Harnessing by Enhancement of Flow Induced Motion using Passive Turbulence Control. Ph.D. Thesis, University of Michigan, Ann Arbor, MI, USA, 2010.

11. Park, H.; Bernitsas, M.M.; Kumar, R.A. Selective roughness in the boundary layer to suppress flow-induced motions of circular cylinder at 30,000 < Re < 120,000. J. Offshore Mech. Arct. Eng. 2012, 134, 041801(1-7).

12. Park, H.; Kumar, R.A.; Bernitsas, M.M. Enhancement of flow-induced motion of rigid circular cylinder on springs by localized surface roughness at $3 \times 10^{4} \leq \operatorname{Re} \leq 1.2 \times 10^{5}$. Ocean. Eng. 2013, 72, 403-415. [CrossRef]

13. Ding, L.; Zhang, L.; Wu, C.; Mao, X.; Jiang, D. Flow induced motion and energy harvesting of bluff bodies with different cross sections. Energy Convers. Manag. 2015, 91, 416-426. [CrossRef]

14. Khalak, A.; Williamson, C.H.K. Dynamics of a hydroelastic cylinder with very low mass and damping. J. Fluid Struct. 1996, 10, 455-472. [CrossRef]

15. Khalak, A.; Williamson, C.H.K. Fluid forces and dynamics of a hydroelastic structure with very low mass and damping. J. Fluid Struct. 1997, 11, 973-982. [CrossRef]

16. Khalak, A.; Williamson, C.H.K. Motions, forces and mode transitions in vortex-induced vibrations at low mass-damping. J. Fluid Struct. 1999, 13, 813-851. [CrossRef]

17. Huang, S. VIV suppression of a two-degree-of-freedom circular cylinder and drag reduction of a fixed circular cylinder by the use of helical grooves. J. Fluid Struct. 2011, 27, 1124-1133. [CrossRef] 
18. Williamson, C.H.K.; Govardhan, R. A brief review of recent results in vortex-induced vibrations. J. Wind Eng. Ind. Aerod. 2008, 96, 713-735. [CrossRef]

19. Williamson, C.H.K.; Govardhan, R. Vortex-Induced Vibrations. Annu. Rev. Fluid Mech. 2004, 36, $413-455$. [CrossRef]

20. Guilmineau, E.; Queutey, P. A numerical simulation of vortex shedding from an oscillating circular cylinder. J. Fluid Struct. 2002, 16, 773-794. [CrossRef]

21. Wu, X.; Ge, F.; Hong, Y. A review of recent studies on vortex-induced vibrations of long slender cylinders. J. Fluid Struct. 2012, 28, 292-308. [CrossRef]

22. Bearman, P.W. Circular cylinder wakes and vortex-induced vibrations. J. Fluid Struct. 2011, 27, $648-658$. [CrossRef]

23. Blevins, R.D. Flow-induced vibration. Van Nostrand Reinhold 1977, 80, 6. [CrossRef]

24. Alonso, G.; Meseguer, J.; Pérez-Grande, I. Galloping stability of triangular cross-sectional bodies: A systematic approach. J. Wind Eng. Ind. Aerod. 2007, 95, 928-940. [CrossRef]

25. Alonso, G.; Valero, E.; Meseguer, J. An analysis on the dependence on cross section geometry of galloping stability of two-dimensional bodies having either biconvex or rhomboidal cross sections. Eur. J. Mech. $B$ Fluids 2009, 28, 328-334. [CrossRef]

26. Alonso, G.; Meseguer, J.; Sanz-Andrés, A.; Valero, E. On the galloping instability of two-dimensional bodies having elliptical cross-sections. J. Wind Eng. Ind. Aerod. 2010, 98, 438-448. [CrossRef]

27. Nakamura, Y.; Hirata, K.; Kashima, K. Galloping of a Circular Cylinder in the Presence of a Splitter Plate. J. Fluid Struct. 1994, 8, 355-365. [CrossRef]

28. Zhu, H.; Yao, J. Numerical evaluation of passive control of VIV by small control rods. Appl. Ocean. Res. 2015, 51, 93-116. [CrossRef]

29. Griffith, M.D.; Lo Jacono, D.; Sheridan, J.; Leontini, J.S. Flow-induced vibration of two cylinders in tandem and staggered arrangements. J. Fluid Mech. 2017, 833, 98-130. [CrossRef]

30. Xu, W.; Ji, C.; Sun, H.; Ding, W.; Bernitsas, M.M. Flow-Induced Vibration and Hydrokinetic Power Conversion of Two Staggered Rough Cylinders for $2.5 \times 10^{4}<\operatorname{Re}<1.2 \times 10^{5}$. J. Offshore Mech. Arct. Eng. 2018, 140, 021905(1-8).

31. Ding, L.; Zhang, L.; Wu, C.M.; Kim, E.S.; Bernitsas, M.M. Numerical Study on the Effect of Tandem Spacing on Flow-Induced Motions of Two Cylinders With Passive Turbulence Control. J. Offshore Mech. Arct. Eng. 2017, 139, 8 .

32. Kim, S.; Alam, M.M.; Sakamoto, H.; Zhou, Y. Flow-induced vibrations of two circular cylinders in tandem arrangement. Part 1: Characteristics of vibration. J. Wind Eng. Ind. Aerod. 2009, 97, 304-311. [CrossRef]

33. Haider, B.A.; Sohn, C.H. Effect of spacing on a pair of naturally oscillating circular cylinders in tandem arrangements employing IB-LB methods: Crossflow-induced vibrations. Int. J. Mech. Sci. 2018, 142, 74-85. [CrossRef]

34. Lan, K.; Sun, H.; Bernitsas, M.M. Two Tandem Cylinders With Passive Turbulence Control in Flow-Induced Vibration: Relation of Oscillation Patterns to Frequency Response. J. Offshore Mech. Arct. Eng. 2018, 140, 031803. [CrossRef]

35. Qin, B.; Alam, M.M.; Ji, C.N.; Liu, Y.; Xu, S.J. Flow-induced vibrations of two cylinders of different natural frequencies. Ocean. Eng. 2018, 155, 189-200. [CrossRef]

36. Jung, S.Y.; Kim, J.J.; Park, H.W.; Lee, S.J. Comparison of flow structures behind rigid and flexible finite cylinders. Int. J. Mech. Sci. 2018, 142, 480-490. [CrossRef]

37. Xu, W.H.; Ma, Y.X.; Cheng, A.K.; Yuan, H. Experimental investigation on multi-mode flow-induced vibrations of two long flexible cylinders in a tandem arrangement. Int. J. Mech. Sci. 2018, 135, 261-278. [CrossRef]

38. Ma, C.H.; Sun, H.; Bernitsas, M.M. Nonlinear Piecewise Restoring Force in Hydrokinetic Power Conversion Using Flow-Induced Vibrations of Two Tandem Cylinders. J. Offshore Mech. Arct. Eng. 2018, 140, 17. [CrossRef]

39. Behara, S.; Ravikanth, B.; Chandra, V. Vortex-induced vibrations of three staggered circular cylinders at low Reynolds numbers. Phys. Fluids 2017, 29, 15. [CrossRef]

40. Chen, W.L.; Ji, C.N.; Williams, J.; Xu, D.; Yang, L.H.; Cui, Y.T. Vortex-induced vibrations of three tandem cylinders in laminar cross-flow: Vibration response and galloping mechanism. J. Fluid Struct. 2018, 78, 215-238. [CrossRef] 
41. Kim, E.S.; Bernitsas, M.M. Performance prediction of horizontal hydrokinetic energy converter using multiple-cylinder synergy in flow induced motion. Appl. Energy 2016, 170, 92-100. [CrossRef]

42. Samanta, A.; Vinuesa, R.; Lashgari, I.; Schlatter, P.; Brandt, L. Enhanced secondary motion of the turbulent flow through a porous square duct. J. Fluid Mech. 2015, 784, 681-693. [CrossRef]

43. Spalart, P.; Allmaras, S. A one-equation turbulence model for aerodynamic flows. Rech. Aerosp. 1994, 1, 5-21.

44. Travin, A.; Shur, M.; Strelets, M.; Spalart, P. Detached-Eddy Simulations Past a Circular Cylinder. Flow Turbul. Combust. 2000, 63, 293-313. [CrossRef]

45. Zdravkovich, M.M. Flow around Circular Cylinders Volume 1: Fundamentals; Oxford University Press: Oxford, UK, 1997.

46. Vinuesa, R.; Bartrons, E.; Chiu, D.; Dressler, K.M.; Rueedi, J.D.; Suzuki, Y.; Nagib, H.M. New insight into flow development and two dimensionality of turbulent channel flows. Exp. Fluids 2014, 55, 1-14. [CrossRef]

47. Ding, L.; Zhang, L.; Bernitsas, M.M.; Chang, C.-C. Numerical simulation and experimental validation for energy harvesting of single-cylinder VIVACE converter with passive turbulence control. Renew. Energy 2016, 85, 1246-1259. [CrossRef]

48. Williamson, C.; Roshko, A. Vortex formation in the wake of an oscillating cylinder. J. Fluid Struct. 1988, 2, 355-381. [CrossRef]

49. Wu, W.; Bernitsas, M.M.; Maki, K. RANS simulation versus experiments of flow induced motion of circular cylinder with passive turbulence control at 35,000<Re $<130,000$. J. Offshore Mech. Arct. Eng. 2014, $136,041802$.

(C) 2018 by the authors. Licensee MDPI, Basel, Switzerland. This article is an open access article distributed under the terms and conditions of the Creative Commons Attribution (CC BY) license (http:/ / creativecommons.org/licenses/by/4.0/). 